Article

\title{
Commuter Bus Operation Rules under Two Traffic Scenarios and Two Weather Conditions: Naturalistic Driving Study on Vehicle Speed and Clearance
}

\author{
Qiuju Huang ${ }^{1,2}$, Shumin Feng ${ }^{1, *}$, Guosheng Zhang ${ }^{3}$, Yu Zhang ${ }^{2}$ and Yong Adilah Shamsul Harumain ${ }^{4}$ \\ 1 School of Transportation Science and Engineering, Harbin Institute of Technology, Harbin 150001, China; \\ qiuju99@163.com \\ 2 School of Automobile, Harbin Vocation and Technical College, Harbin 150081, China; haitian8850@163.com \\ 3 Research Institute of Highway, Ministry of Transport, Beijing 100088, China; gs.zhang@rioh.cn \\ 4 Center of Transportation, University Malaya, Kuala Lumpur 50603, Malaysia; adilah_shamsul@um.edu.my \\ * Correspondence: fsm@hit.edu.cn; Tel.: +86-139-4506-9995
}

check for

updates

Citation: Huang, Q.; Feng, S.; Zhang,

G.; Zhang, Y.; Harumain, Y.A.S.

Commuter Bus Operation Rules under Two Traffic Scenarios and Two Weather Conditions: Naturalistic

Driving Study on Vehicle Speed and Clearance. Sustainability 2022, 14 ,

2473. https://doi.org/10.3390/ su14042473

Academic Editors: Armando Cartenì and Marc A. Rosen

Received: 23 November 2021

Accepted: 18 February 2022

Published: 21 February 2022

Publisher's Note: MDPI stays neutral with regard to jurisdictional claims in published maps and institutional affiliations.

Copyright: () 2022 by the authors. Licensee MDPI, Basel, Switzerland. This article is an open access article distributed under the terms and conditions of the Creative Commons Attribution (CC BY) license (https:/ / creativecommons.org/licenses/by/ $4.0 /)$.

\begin{abstract}
This study provides insights into the building of environmentally and socially sustainable and livable cities by investigating commuter buses' vehicle speed and clearance, considering two traffic scenarios (working days and weekends) and two weather conditions on urban roads. Thirty participants drove ten different routes during natural driving. The drivers were observed under the following traffic conditions: free flow (Grade I), steady flow (Grades II and III), unsteady flow (Grade IV), working days and weekends, and sunny and heavy snow weather. A method for collecting accurate traffic flow data was developed using a radar sensor to measure the real-time distance between vehicles. The real-time vehicle spacing and speed were detected using a radar sensor and a mobile app, respectively. The results showed that speed decreased obviously from $11.2 \%$ to $16.5 \%$ on working days compared to a similar situation on weekends, especially in heavy snow weather (from $33.8 \%$ to $40.7 \%$ ). The lowest average speed was obtained in the traffic environment Grade IV. Commuter buses maintained a minimum vehicle clearance during working or heavy snow days in traffic environment Grade IV. Policymakers should consider the insights of this study to develop new, dynamic commuter schedules under diverse conditions.
\end{abstract}

Keywords: natural driving; commuter bus; driving speed; vehicle clearance

\section{Introduction}

Vehicles play a prominent role in the motion patterns of almost everyone in the 21st century. Thus, clear rules are a necessary precondition for safe and fluent traffic [1]. In particular, commuter buses are a nonprofit transport tool for enterprise employee commuting that usually follows a fixed time and route [2]. For instance, SAIC Volkswagen Co., Ltd. has an average of 87 commuters per day, with 287 routes, and 250 stations for employees [3]. Another report suggests that people in Tiantongyuan, Beijing spend $62.5 \mathrm{~min}$ commuting in the morning [4]. Therefore, commuter buses play a crucial role in transportation systems [5]. Moreover, urban public transport is gaining significance in today's world. For instance, urban public transport has a place in the eleventh Sustainable Development Goal of "Sustainable cities and communities" [6].

Commuter buses can reduce the traffic burden, traffic congestion, energy shortages, and environmental pollution. These buses are essential for building environmentally and socially sustainable and livable cities [7]. For example, practical commuter line design and station-setting reduce the number of vehicles used and the running distance; therefore, decreasing the transportation cost. An accurate commute time reduces the waiting time of commuters at the station, which is especially important during bad weather. Moreover, it improves the comfort of passengers, reduces commuter fatigue, and improves work 
efficiency [8]. However, optimizing the commuting time must rely on exploring the operation rules of commuter vehicles, i.e., speed or vehicle clearance, on working and non-working days, as well as in sunny or snowy weather.

A previous study showed that driving on weekdays and non-weekdays affects the average speed of vehicles, including commuter buses [9]. The study reported that the cumulative distribution proportion of vehicle hours traveled (VHT) was $81.24 \%$ and $76.96 \%$ on weekdays and non-working days, respectively, in Beijing. These results indicate that the average speed of vehicle travel on weekdays is lower than on weekends. Therefore, we can conclude that the average speed of commuters on weekdays and weekends differs. Furthermore, exploring the rules to improve commuter efficiency is essential.

Other factors, such as bad weather and the effect of commuter bus rules, have also been studied. For instance, some scholars [10] concluded that the headway in heavy snow weather was significantly different from that in sunny weather, and heavy snow substantially affects the smoothness of traffic flow. Moreover, some scholars [11] concluded that the average speed of vehicles decreased from 44 to 26 miles/h (40\%) in heavy snow in Las Vegas. A study also showed that the flow of expressways decreased by approximately $39 \%$, speeds decreased by $10-20 \mathrm{~km} / \mathrm{h}$, arrival time intervals generally increased by $2-4 \mathrm{~s}$, and saturated flow rate decreased by approximately $25 \%$ in Beijing during heavy snow [12]. Thus, we can surmise that snowy weather correlates with the operation rules of commuter buses because it is an important part of traffic flow.

Speed and vehicle clearance are important indicators reflecting traffic flow operation rules [13]. Speed operations have been widely studied; however, less attention has been paid to commuter buses. Therefore, concrete rules related to the speed or vehicle clearance of commuter buses should be found for experts to consider when designing or optimizing commuting routes and schedules for automatic buses.

Currently, the acquisition methods for real-time speed measurement include coil detection and video images [14], which offer high detection accuracy. However, the realtime distance between vehicles is difficult to measure directly and is usually calculated indirectly from headway [15]. Hence, it is necessary to develop a new method for measuring vehicle clearance more directly and accurately when the car is moving.

According to some scholars [16], studies on commuting have rarely considered elements other than commuting mode selection and route optimization. For example, scholars [17] combined mobile phone signaling data with point of interest data to propose a method for identifying the service areas of commuter CB and travel demand. Some scholars [18] explored the decision-making behavior of commuters at a bus station of departure during morning peak hours. Some scholars [19] developed a systematic toolkit for demand estimation and route planning for long-distance commuter bus lines. Some scholars [20] proposed a method for extracting potential $\mathrm{CCB}$ passengers from regular bus passengers based on the bus smart card data; the method guides bus operators in designing CCB lines and allocating vehicle capacities on different lines. Some scholars [21] established a safety risk evaluation system that evaluates the safety status of a commuting system through a grey analytic hierarchy process. Some scholars [22] showed that GHG emissions can be reduced by expanding commuter bus services and providing incentives to shift commuters from private cars to transit; the method is universal, so itcan be applied in other cities globally. These developments demonstrate the need to pay more attention to research on commuter buses, which complement urban public transport, reduce residents' travel costs, alleviate urban traffic congestion, reduce vehicle exhaust emissions, and contribute to the sustainable development of society.

This study further extends previous work by comparing different traffic flow states, considering speed behavior and vehicle clearance. To the authors' best knowledge, no other study has been performed in this regard. Thus, the knowledge gap to be filled in this study is associated with the effects of speed and vehicle clearance of commuter buses when commuting on working and non-working days, considering four traffic flows under two weather conditions in a naturalistic driving environment. These research results can 
help the department of public transportation management adjust commuter schedules as well as improve commuters' satisfaction when travelling and the efficiency of the public transportation system.

The remainder of this paper is organized as follows: Section 2 presents the survey and analysis method, participants, traffic routes and scenarios, and data collection and analysis methods. The results of the survey are presented in Section 3. In Section 4, the results are analyzed and discussed. Section 5 concludes this paper and provides directions for future research.

\section{Methods and Materials}

\subsection{Participants}

For this study, a varied and realistic sample of Chinese commuter bus drivers were recruited in terms of age and driving experience. We reviewed existing similar studies based on NDS and finally selected 30 commuter drivers. In total, 30 professional commuter bus drivers volunteered for this study. All participants gave their informed consent for inclusion prior to participation. The study was conducted in accordance with the Declaration of Helsinki, and the protocol was approved by the Ethics Committee of China Association for Ethical Studies (NO. 3965). Moreover, all had bus driving licenses for more than 12 months and an average of 10.5 years (range $=2-24$ years; $S D=5.28$ ). As shown in Table 1 , there were 19 male and 11 female participants, and the average reported age was 41.4 years (range $=35-48$ years; $\mathrm{SD}=2.81$ ). Approximately $80 \%$ of the participants drove more than 15,000 km annually, while the average in China for 2017 was 13,583 km (Sun et al., 2017). All drivers had good vision.

Table 1. Traffic environment states for each level.

\begin{tabular}{ccccc}
\hline & $\begin{array}{c}\text { Grade I } \\
\text { (Free Flow) }\end{array}$ & $\begin{array}{c}\text { Grade II } \\
\text { (Intermediate Range } \\
\text { of Steady Flow) }\end{array}$ & $\begin{array}{c}\text { Grade III } \\
\text { (Lower Half of } \\
\text { Steady Flow) }\end{array}$ & $\begin{array}{c}\text { Grade IV } \\
\text { (Unsteady Flow) }\end{array}$ \\
\hline $\begin{array}{c}\text { Traffic volume } \\
\text { (pcu/30 } \mathrm{m} \\
\text { ahead) }\end{array}$ & $\leq 3$ & $(3,7)$ & & \\
$\begin{array}{c}\text { V } / \mathrm{C} \\
\text { Evaluation score }\end{array}$ & $\leq 0.25$ & $(0.25,0.53)$ & {$[7,11)$} & $\geq 11$ \\
\hline
\end{tabular}

\subsection{Vehicles and Buses Seats}

The vehicles used were all commuter buses, containing 39 (Figure 1) or 49 (Figure 2) seats, and the driver's seat was on the left-hand side. The length of the bus was $8995 \mathrm{~mm}$ or 10,990 mm, with a width of $2500 \mathrm{~mm}$ and a height of $3360 \mathrm{~mm}$ or $3440 \mathrm{~mm}$.

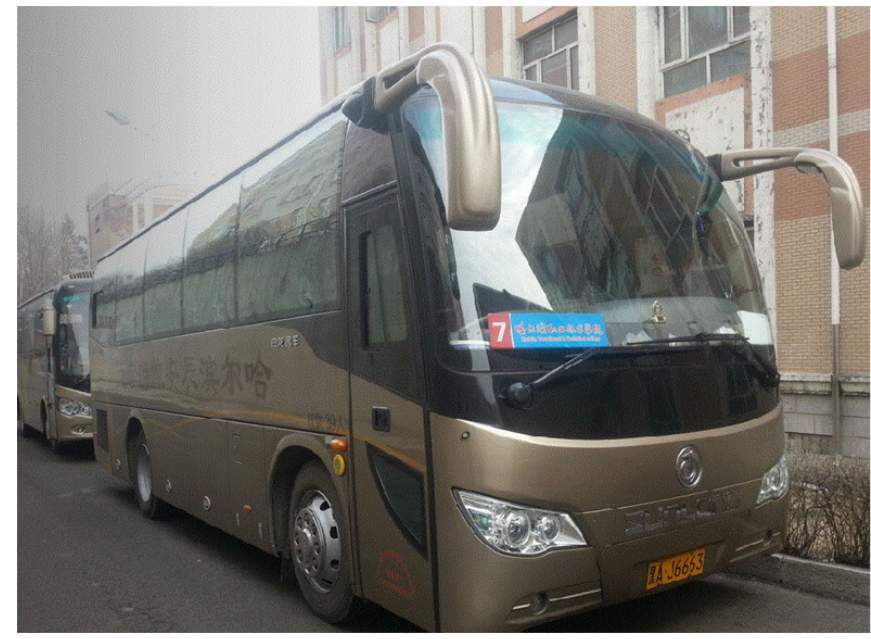

Figure 1. Bus with 39 seats. 


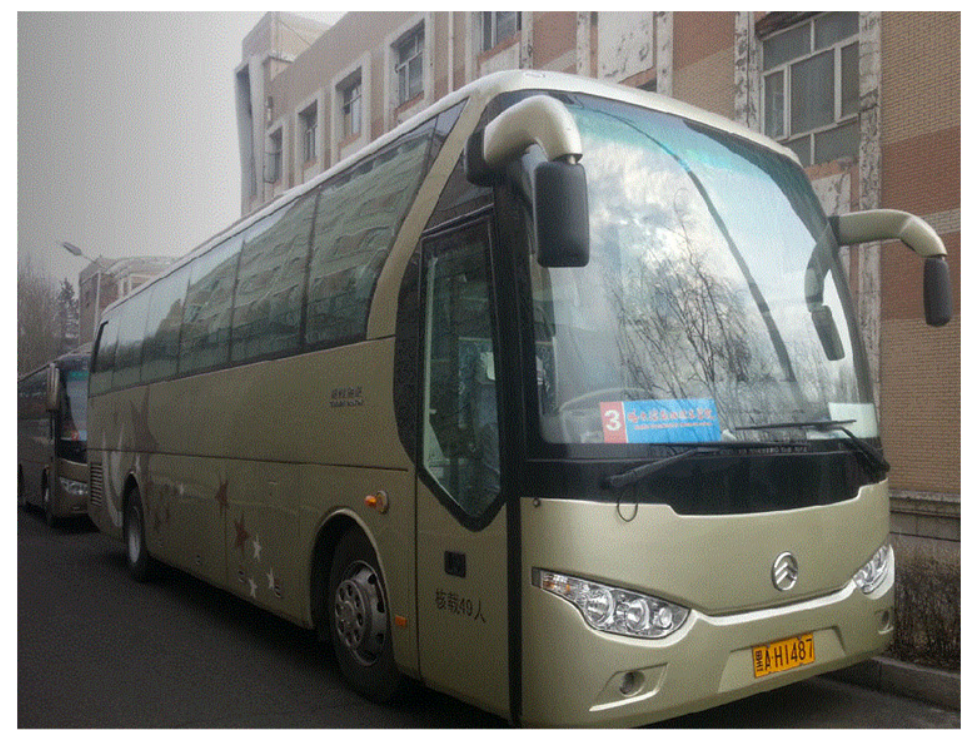

Figure 2. Bus with 49 seats.

\subsection{Experimental Routes and Scenarios}

As shown in Figures 3 and 4, the roads were urban roads, comprising ten routes containing 84 stations. The total distance of the ten urban roads was approximately $180.4 \mathrm{~km}$ in Harbin, China. The ten roads comprised two or three lanes in each direction, and the speed limit on the varied from 50 to $60 \mathrm{~km} / \mathrm{h}$. The ten routes were the same for working or weekend days and good or bad weather. This condition allowed for evaluating the effects of speed and vehicle clearance.

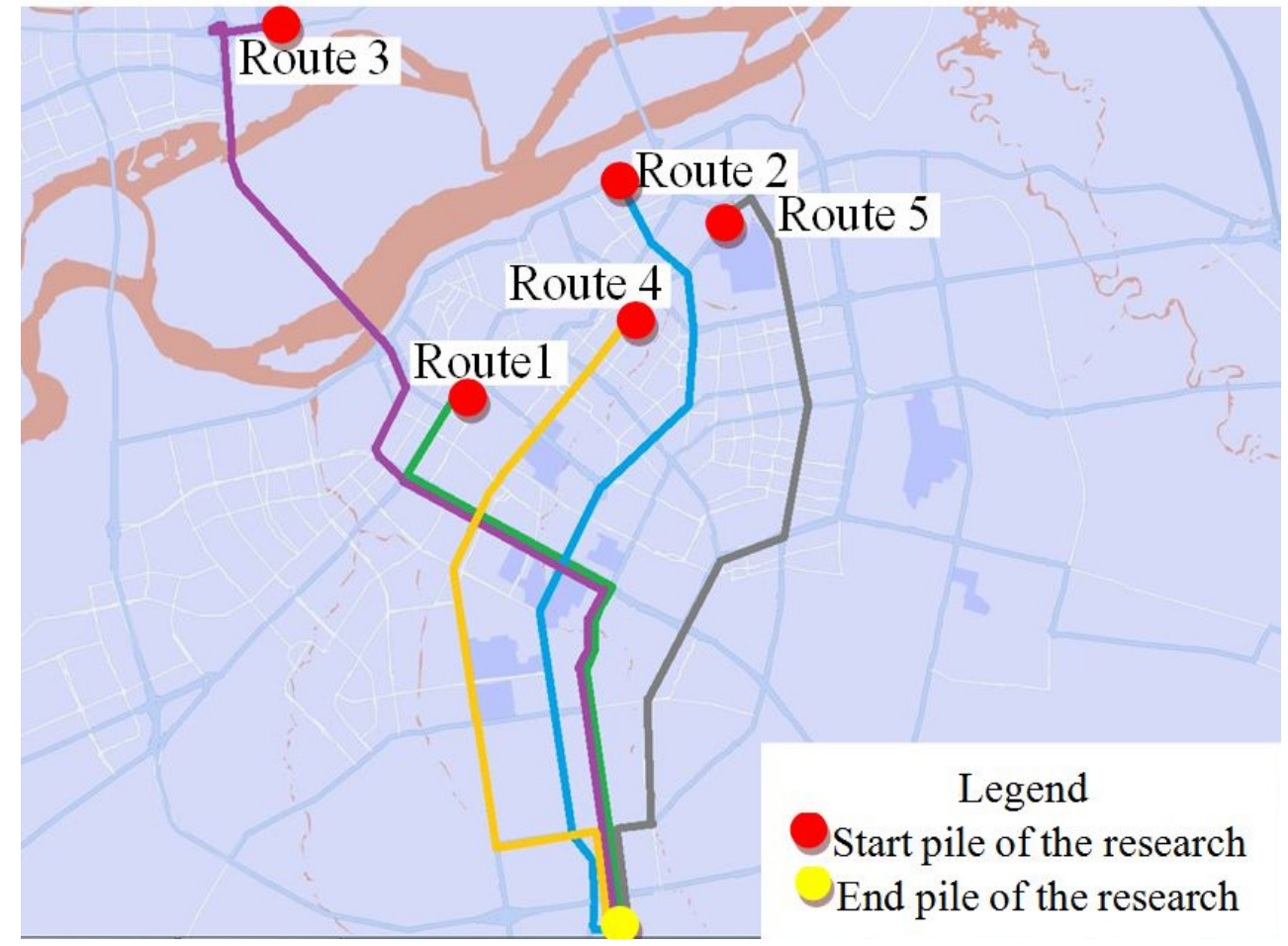

Figure 3. Selected experimental roads NO. 1-5. 


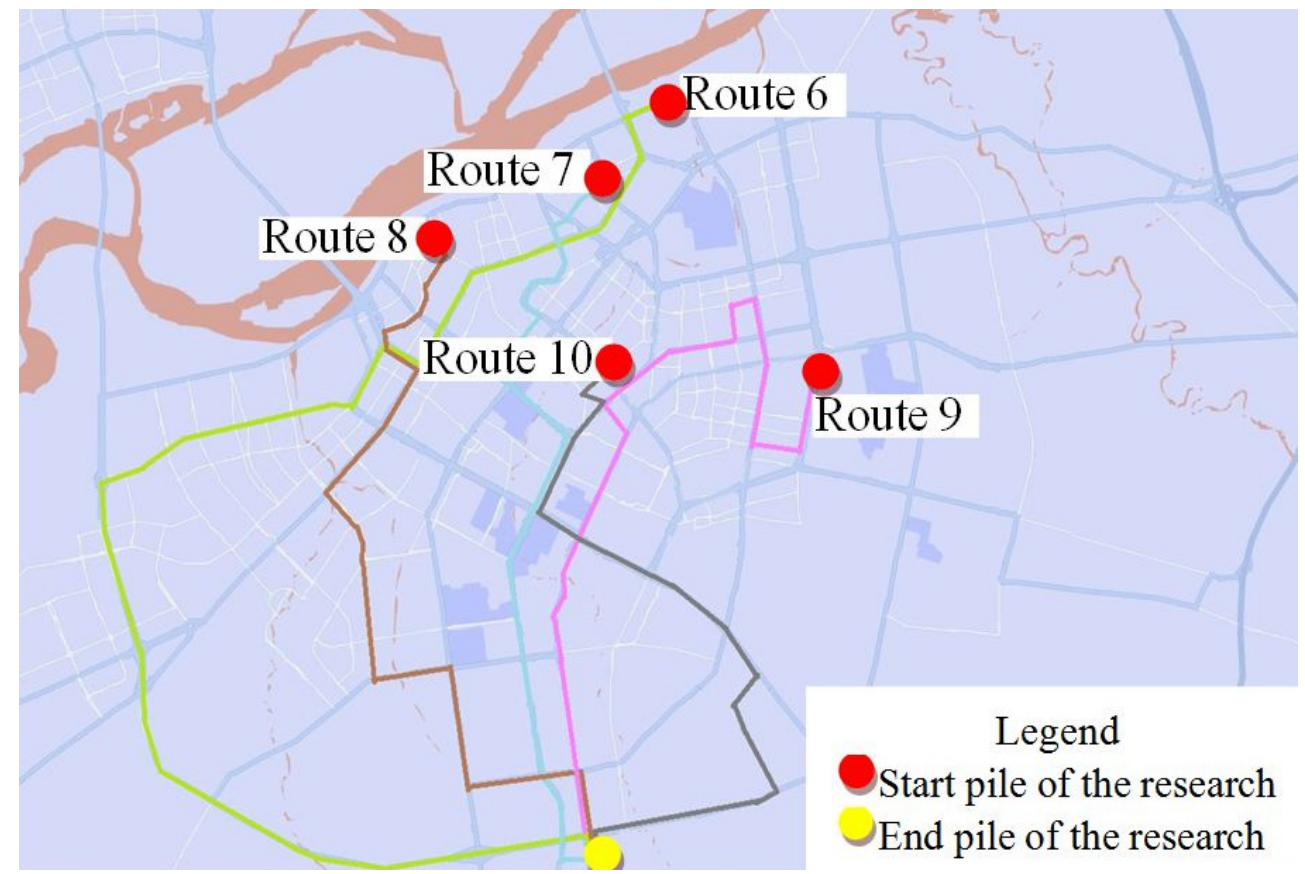

Figure 4. Selected experimental roads NO. 6-10.

Natural driving behavior research (NDS) collects driving behavior data in a natural driving state in a real traffic environment without external interference [23]. Essentially, the extracted NDS data are true and accurate, thus, the method is increasingly being applied [24,25]. The naturalistic driving data of all commuter vehicles were collected during the morning and evening commuting hours.

The traffic environmental conditions were described by traffic flow states and divided into four grades according to saturation [26,27] (see Table 1). The driver freely selects the driving speed in Grade I (free flow) but is limited to a certain degree when the traffic environment saturation is Grade II (intermediate range of steady flow). If the driver is in Grade III (lower half of steady flow), the driving speed is limited substantially; whereas the driver has no freedom to select the driving speed in Grade IV (unsteady flow). Figure 5 shows real-life traffic flow states.

Free flow

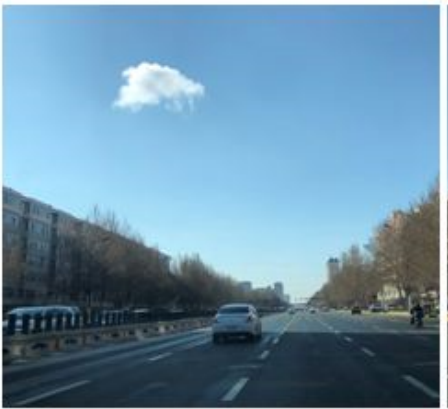

Steady flow

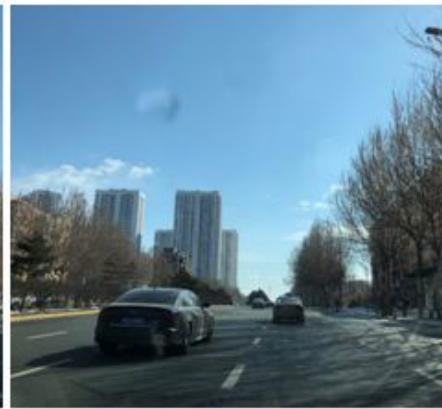

Steady flow

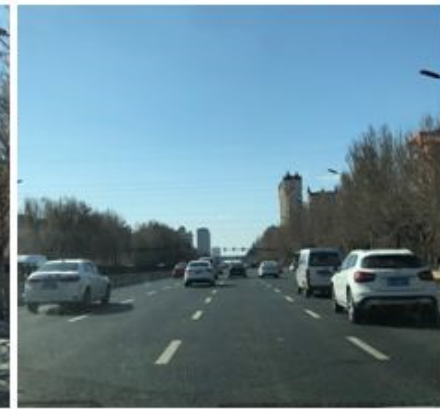

Unsteady flow

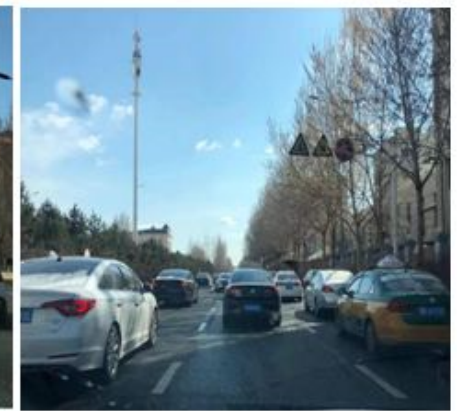

Figure 5. Photographs illustrating the traffic flow state.

The traffic scenarios considered working days or weekends. The working day refers to Monday to Friday, whereas the weekend refers to Saturday only. The traffic condition also contains good and bad weather, good weather refers to sunny days, and bad weather refers to heavy snow days. Heavy snow is considered bad weather because it seriously affects the stable operation of urban traffic in the cold areas of north China [28]. 


\subsection{Procedure}

During the introductory part, all participants completed a questionnaire with general information and demographic questions. Subsequently, they received a commuter schedule that contained ten lines. Each route had three drivers as they usually work, that is, each driver would drive one day and rest for two days. All drives were similar to normal work conditions to reduce the potential order and learning effects.

According to the weather forecast, participants were instructed to drive naturally throughout the experiment for 12 consecutive days, including four days of heavy snow. The experiment was conducted during commuting time every day, as usual, in the morning from 6:00 a.m. to 8:00 a.m. and in the afternoon from 16:00 p.m. to 18:30 p.m.

\subsection{Data Collection and Analysis}

The data contained traffic volume data and naturalistic driving data. The traffic volume data were obtained from Harbin Traffic Management and Command Center. According to the measured traffic flow data, the corresponding saturation was calculated, and different traffic flow states were classified for different saturations. The classification was considered for the division standard for analyzing the distribution of speed and headway in different traffic flow states (Table 1).

The naturalistic driving data were collected using a camera, smartphone, and laptop (see Figure 6 and Table 2). The time settings of all equipment were unified and synchronized to Beijing time. All equipment was turned on simultaneously at the beginning of the test. The naturalistic driving data were sampled in a timely manner to ensure that the driving parameters were at a constant time interval. For this experiment, a constant time interval of $1 \mathrm{~s}$ was used for speed, and the vehicle clearance was presented at a 200-Hz refresh rate. The time-frequency is usually set between 30 and $250 \mathrm{~Hz}$ [29].

(a)
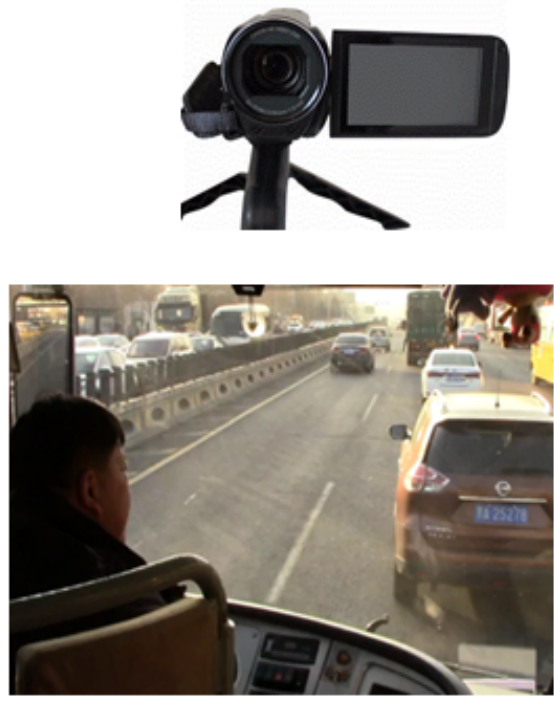

(b)
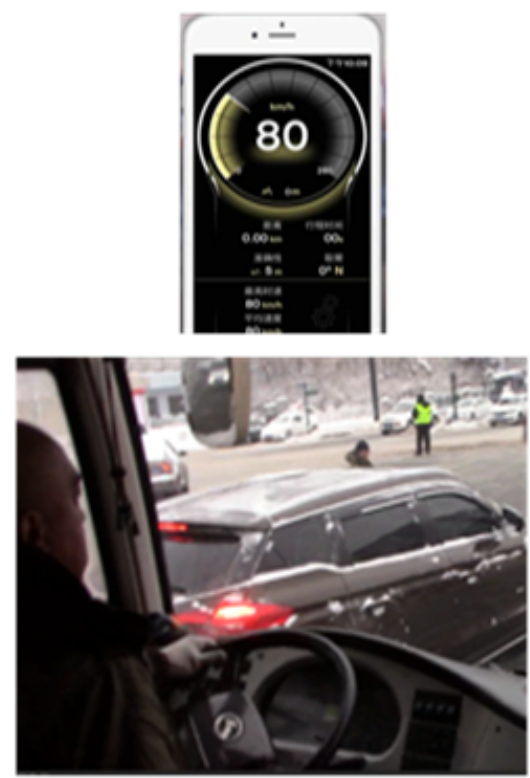

(c)
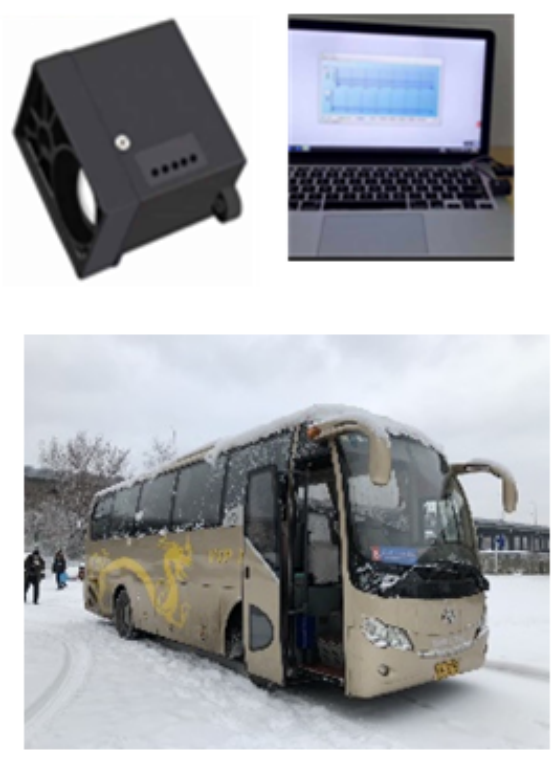

Figure 6. Illustrations of naturalistic driving data collection devices: (a) camera; (b) smartphone; (c) laser distant sensor and laptop. 
Table 2. List of naturalistic driving data collection devices.

\begin{tabular}{|c|c|c|c|c|}
\hline Device & Location & Function & Data Collection & Result \\
\hline $\begin{array}{c}\text { Camera } \\
\text { (Canon HF 806) }\end{array}$ & $\begin{array}{l}\text { Inside bus } \\
\text { behind the } \\
\text { driver }\end{array}$ & Recording & $\begin{array}{c}\text { Weather and road } \\
\text { environment } \\
\text { Manipulation behavior }\end{array}$ & \multirow{3}{*}{$\begin{array}{l}\text { Naturalistic } \\
\text { driving data }\end{array}$} \\
\hline $\begin{array}{l}\text { Smartphone } \\
\text { (iPhone } 8 \text { plus) }\end{array}$ & $\begin{array}{l}\text { First-row seats } \\
\text { inside the bus }\end{array}$ & $\begin{array}{l}\text { GPS Speed (an } \\
\text { App) } \\
\text { Screen recording }\end{array}$ & $\begin{array}{l}\text { Measuring vehicle operation } \\
\text { data in real time (speed, } \\
\text { mileage, etc.) } \\
\text { Recording vehicle operation } \\
\text { data of the entire rout }\end{array}$ & \\
\hline $\begin{array}{l}\text { Laser distance } \\
\text { sensor (SK-Z-5) } \\
\text { and laptop } \\
\text { (Lenovo) }\end{array}$ & $\begin{array}{l}\text { In the middle of } \\
\text { the front outside } \\
\text { the bus and the } \\
\text { laptop inside }\end{array}$ & $\begin{array}{l}\text { Measuring } \\
\text { Recording }\end{array}$ & $\begin{array}{l}\text { Displaying real-time vehicle } \\
\text { spacing curve and data } \\
\text { Recording vehicle spacing } \\
\text { curve and data of the entire } \\
\text { route }\end{array}$ & \\
\hline
\end{tabular}

The speed and vehicle clearance were monitored during the entire trip. The speed data obtained from the smartphone were PS speed data obtained from satellites when driving, and the difference between the actual speed and GPS-measured speed is approximately $2-3 \mathrm{~km} / \mathrm{h}[30]$. The data were processed before analysis. For all statistical analyses performed in SAS 9.4, TS leVel 1 M3, the type-I error $\alpha$ was set to 0.05 . The normality assumption was verified based on normal probability plots.

\subsubsection{Speed}

The real-time vehicle speed was recorded using a smartphone app with GPS Speed. All data were collected while each driver was naturally driving the bus. A camera was mounted inside the bus to record the traffic states and the driver's maladaptive behaviors for further research in this study.

\subsubsection{Vehicle Clearance}

A sensor, fixed on the front of the commuter bus, collected the real-time distance between the test bus and the vehicle ahead. Data and video images were recorded using the Camtasia Studio 8.0 software on a laptop.

\section{Results}

\subsection{Speed}

\subsubsection{Working Days and Weekend}

The linear mixed model analysis with "traffic status" $\times$ "traffic scenarios" (working days and weekends), routes as fixed effects, and drivers as random effects revealed highly significant main effects on the average speed for "traffic status", T $(49,49)=28.26, p<0.0001$, and "traffic scenarios", $\mathrm{T}(49,49)=13.88, p<0.0001$.

Because the interaction between the "traffic status" and the "traffic scenarios" (working days and weekends) was significant, all interpretations were performed on the level of the interaction. The mean speeds for all combinations of "traffic status" and working days and weekends are shown in Figure 7. The significant interaction between "traffic status" and "working days \& weekend" was further studied by comparing two by two for each type of day of the four traffic statuses $(2 \times 8$ comparisons). Moreover, for each traffic status, both types of days were compared (four comparisons). The comparisons were performed at a significance level of $\alpha / 25=0.002$ to control the overall type-I error $\alpha$ of 0.05 (Bonferroni correction for multiple comparisons). The results of the comparisons are listed in Table 3. The entries in the table marked with an asterisk correspond to the 0.002 significance level. 
Speed

Traffic status $\times$ Days $(\mathrm{p}<0.001)$

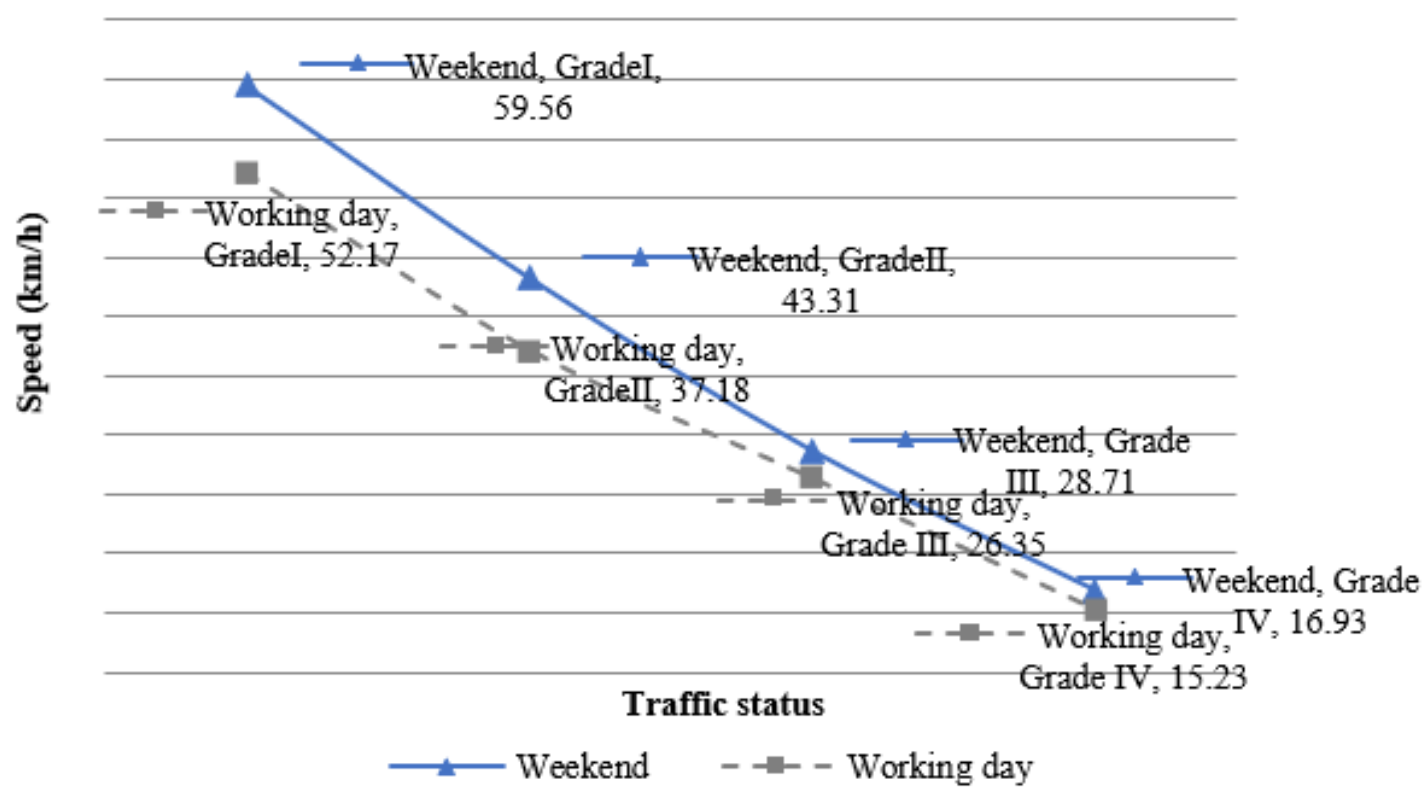

Figure 7. Two-way interaction effect of "traffic status" $\times$ "traffic scenarios" for average speed.

Table 3. Two-way interaction effect, "traffic status" $\times$ "working days \& weekends", for average speed: two-by-two comparisons.

\begin{tabular}{|c|c|c|c|c|c|c|c|c|c|}
\hline Effect & $\begin{array}{l}\text { Traffic } \\
\text { Status }\end{array}$ & $\begin{array}{c}\text { Traffic } \\
\text { Scenarios }\end{array}$ & $\begin{array}{l}\text { Traffic } \\
\text { Status }\end{array}$ & $\begin{array}{c}\text { Traffic } \\
\text { Scenarios }\end{array}$ & Estimate & $\begin{array}{l}\text { Standard } \\
\text { Error }\end{array}$ & DF & $t$-Value & $\operatorname{Pr}>|t|$ \\
\hline \multirow[t]{4}{*}{ Traffic status $\times$ day } & Grade I & Weekend & Grade I & Working day & 7.71 & 4.43 & 58 & 17.58 & $<0.0001$ \\
\hline & Grade I & Weekend & Grade I & Working day & 5.84 & 2.34 & 58 & 16.35 & $<0.0001$ \\
\hline & Grade III & Weekend & Grade III & Working day & 2.35 & 1.89 & 58 & 9.55 & $<0.0001$ \\
\hline & Grade IV & Weekend & Grade IV & Working day & 1.69 & 1.71 & 58 & 7.57 & $<0.0001$ \\
\hline \multirow[t]{6}{*}{ Traffic status $\times$ day } & Grade I & Working day & Grade I & Working day & 13.68 & 3.51 & 58 & 25.58 & $<0.0001$ \\
\hline & Grade I & Working day & Grade III & Working day & 24.98 & 3.73 & 58 & 51.46 & $<0.0001$ \\
\hline & Grade I & Working day & Grade IV & Working day & 36.10 & 4.08 & 58 & 67.95 & $<0.0001$ \\
\hline & Grade I & Working day & Grade III & Working day & 10.89 & 1.53 & 58 & 46.53 & $<0.0001$ \\
\hline & Grade I & Working day & Grade IV & Working day & 22.22 & 1.96 & 58 & 74.04 & $<0.0001$ \\
\hline & Grade III & Working day & Grade IV & Working day & 11.11 & 2.01 & 58 & 42.41 & $<0.0100$ \\
\hline \multirow[t]{6}{*}{ Traffic status $\times$ day } & Grade I & Weekend & Grade I & Weekend & 15.81 & 3.19 & 58 & 32.51 & $<0.0001$ \\
\hline & Grade I & Weekend & Grade III & Weekend & 31.08 & 3.14 & 58 & 75.99 & $<0.0001$ \\
\hline & Grade I & Weekend & Grade IV & Weekend & 42.86 & 3.16 & 58 & 104.22 & $<0.0001$ \\
\hline & Grade I & Weekend & Grade III & Weekend & 14.54 & 1.89 & 58 & 50.44 & $<0.0001$ \\
\hline & Grade I & Weekend & Grade IV & Weekend & 26.38 & 1.77 & 58 & 97.62 & $<0.0001$ \\
\hline & Grade III & Weekend & Grade IV & Weekend & 11.78 & 0.77 & 58 & 116.66 & $<0.0001$ \\
\hline
\end{tabular}

The analysis revealed that, except for Grade III and Grade IV, the average speed on urban roads was significantly different for the two traffic scenarios (working days and weekends), with an average speed that was higher for weekends than for working days. For both days, the traffic status with Grade IV significantly resulted in the lowest average speed. In Grade III and Grade IV, the difference in the average speed of the commuter buses between working days and weekends was not significant.

Regarding working days and weekends, half of the average speed differences were significant, specifically, the commuter bus speed difference between working days and weekends in Grade I and Grade II. In particular, the traffic environment conditions in Grade I significantly resulted in the largest average speed difference, with an average speed lower for working days than for weekends. The average speed differences of all four traffic statuses (Grades I-IV) were significant for weekdays or weekends. 


\subsubsection{Weather Condition}

Similar to the traffic scenarios (working days and weekends), the analysis revealed a highly significant main effect on average speed for both "traffic status", T $(43,43)=12.38$, $p<0.0001$, and "weather", T $(102,102)=28.49, p<0.0001$, and a significant interaction effect on average speed for "traffic status" and "weather", T $(59,59)=56.27, p<0.0001$.

Because the interaction effect was significant, this was used to interpret the results. The average speed for all combinations of "traffic status" (Grades I-IV) and "weather" is presented in Figure 8. Moreover, Table 4 provides a detailed examination. Similarly, we considered a significance level of 0.002 for pair-wise comparisons.

Speed

Traffic status $\mathbf{x}$ Weather $(\mathbf{p}<0.001)$

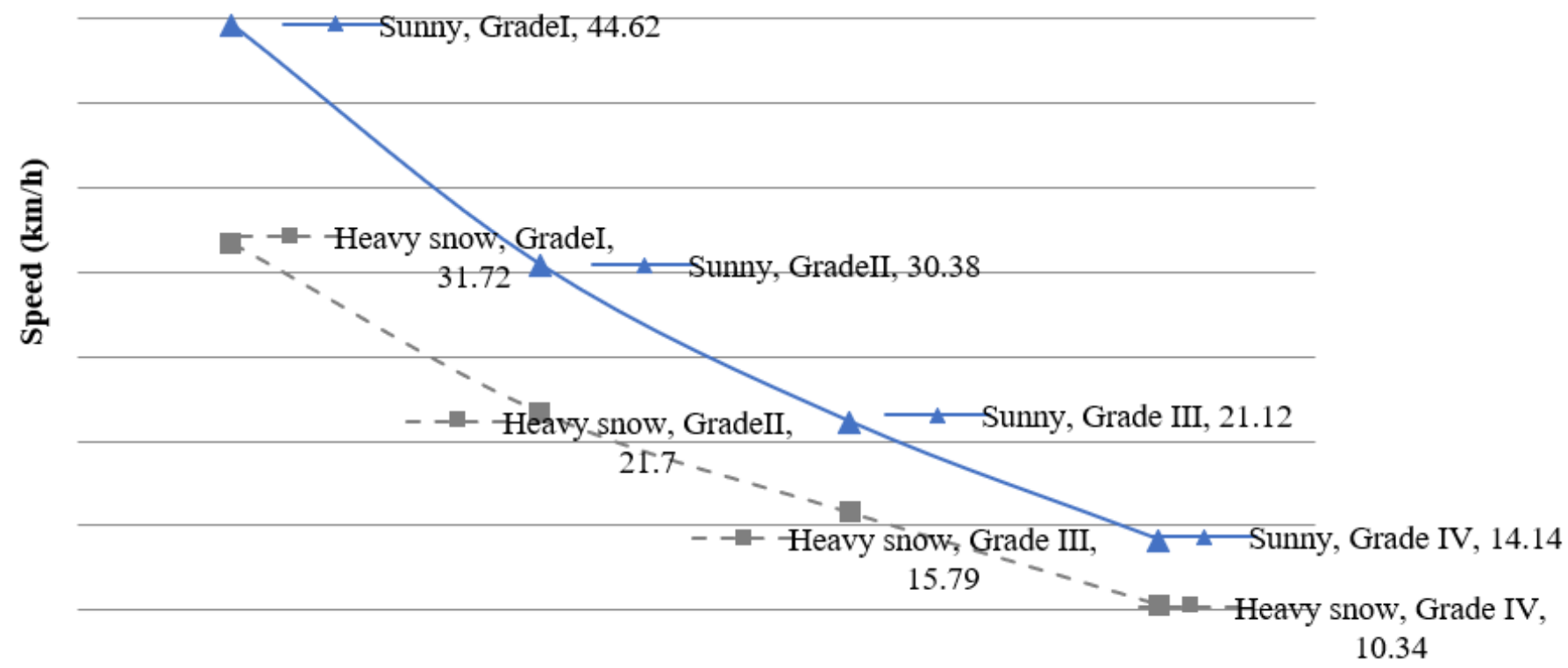

Traffic status

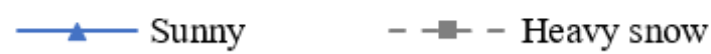

Figure 8. Two-way interaction effect, "traffic status" $\times$ "weather", for the average speed.

The average speed difference in each traffic status (Grades I-IV) was significant, indicating that the average speed of commuter buses on urban roads was lower when the weather was heavy snow (HS) than when sunny (S). For Grade I, the average speed difference of commuter buses between heavy snow days and sunny days was the most significant, with an average speed lower for heavy snow days than for sunny days. For both weather conditions, the traffic state with Grade IV significantly resulted in the lowest average speed. Regardless of the weather conditions, the average speed of commuter buses was the lowest in the heavy snow and traffic state Grade IV. 
Table 4. Two-way interaction effect, "traffic status" $\times$ "weather", for average speed: two-bytwo comparisons.

\begin{tabular}{|c|c|c|c|c|c|c|c|c|c|}
\hline Effect & $\begin{array}{l}\text { Traffic } \\
\text { Status }\end{array}$ & Weather & $\begin{array}{l}\text { Traffic } \\
\text { Status }\end{array}$ & Weather & Estimate & $\begin{array}{c}\text { Standard } \\
\text { Error }\end{array}$ & DF & $t$-Value & $\operatorname{Pr}>|t|$ \\
\hline \multirow[t]{4}{*}{ Traffic status $\times$ weather } & Grade I & Sunny & Grade I & HS & 6.98 & 2.47 & 58 & 28.49 & $<0.0001$ \\
\hline & Grade I & Sunny & Grade I & HS & 4.14 & 1.71 & 58 & 15.80 & $<0.0001$ \\
\hline & Grade III & Sunny & Grade III & HS & 1.44 & 1.12 & 58 & 9.90 & $<0.0001$ \\
\hline & Grade IV & Sunny & Grade IV & HS & 1.81 & 0.95 & 58 & 14.65 & $<0.0001$ \\
\hline \multirow[t]{6}{*}{ Traffic status $\times$ weather } & Grade I & HS & Grade I & HS & 9.79 & 2.19 & 58 & 34.34 & $<0.0001$ \\
\hline & Grade I & HS & Grade III & HS & 15.70 & 2.05 & 58 & 58.90 & $<0.0001$ \\
\hline & Grade I & HS & Grade IV & HS & 21.15 & 2.12 & 58 & 76.69 & $<0.0001$ \\
\hline & Grade I & HS & Grade III & HS & 5.91 & 1.22 & 58 & 37.31 & $<0.0001$ \\
\hline & Grade I & HS & Grade IV & HS & 11.37 & 1.16 & 58 & 75.54 & $<0.0001$ \\
\hline & Grade III & HS & Grade IV & HS & 5.46 & 0.98 & 58 & 42.45 & $<0.0001$ \\
\hline \multirow[t]{6}{*}{ Traffic status $\times$ weather } & Grade I & Sunny & Grade I & Sunny & 12.39 & 2.11 & 58 & 38.37 & $<0.0001$ \\
\hline & Grade I & Sunny & Grade III & Sunny & 21.61 & 2.02 & 58 & 82.24 & $<0.0001$ \\
\hline & Grade I & Sunny & Grade IV & Sunny & 26.71 & 1.96 & 58 & 104.76 & $<0.0001$ \\
\hline & Grade I & Sunny & Grade III & Sunny & 8.75 & 1.18 & 58 & 48.52 & $<0.0001$ \\
\hline & Grade I & Sunny & Grade IV & Sunny & 13.95 & 1.19 & 58 & 77.13 & $<0.0001$ \\
\hline & Grade III & Sunny & Grade IV & Sunny & 5.09 & 0.56 & 58 & 68.83 & $<0.0001$ \\
\hline
\end{tabular}

All traffic statuses (Grades I-IV) presented significant differences in average speed regardless of the weather conditions.

\subsection{Vehicle-to-VehicleDistance}

According to the survey, the vehicle clearance ranged from $1.58 \mathrm{~m}$ to $38.92 \mathrm{~m}$, with a larger distance indicating an increased freedom of choice in driving speed. The vehicle clearance was not large in most commuter buses for each experimental group (median distance in each group <13.82). Figure 9 depicts the impact of different conditions (including weather and traffic scenarios) on the vehicle clearance. A four-level, one-way analysis of traffic conditions revealed significant differences in vehicle clearance, $F(3,435)=4.42$, $p=0.003$. Subsequent $t$-tests revealed that commuter buses driving on weekends reported a significantly higher mean distance $(\mathrm{Md})$ of vehicle-to-vehicle than commuter buses driving on working days ( $\mathrm{Md}=17.42$ and 12.48), $t(196)=2.69, p=0.05 ; \mathrm{d}=0.36,95 \% \mathrm{CI}: 14.22$ to 15.67 , or in heavy snow weather $(\mathrm{Md}=17.42$ and 10.48), $t(194)=3.65, p=0.05 ; \mathrm{d}=0.48$, $95 \%$ CI: 12.97 to 14.93 . Additionally, the vehicle clearance was significantly higher among commuter buses driving in sunny weather conditions than those driving on working days $(\mathrm{Md}=14.89$ and 12.48) $, t(196)=1.51, p=0.05 ; \mathrm{d}=0.20,95 \% \mathrm{CI}: 13.28$ to 14.09 , or in heavy snow weather $(\mathrm{Md}=14.89$ and 10.48), $t(194)=2.40, p=0.05 ; \mathrm{d}=0.32,95 \% \mathrm{CI}: 12.05$ to 13.33. Group differences were present in the vehicle clearance of commuter buses driving on weekends and those driving in sunny weather conditions ( $\mathrm{Md}=17.42$ and 14.89), $t(194)=1.54, p=0.05 ; \mathrm{d}=0.20,95 \% \mathrm{CI}: 15.74$ to 16.57 . Additionally, group differences existed in the vehicle clearance of commuter buses driving on working days and those driving in heavy snow weather conditions ( $\mathrm{Md}=12.48$ and 10.48), $t(194)=1.48, p=0.05$; $\mathrm{d}=0.19,95 \%$ CI: 11.08 to 11.88 .

Post hoc tests using Bonferroni corrections revealed that commuter buses driving on weekends significantly reported a higher vehicle-to-vehicle distance than buses driving on working days $(p=0.05)$. Additionally, commuter buses driving in sunny weather conditions reported significantly greater vehicle clearance than buses driving on heavy snow days $(p=0.042)$. Finally, regression analyses were conducted to assess the effects of traffic scenarios (Grades I-IV) on the vehicle-to-vehicle commuter bus distance across naturalistic driving conditions. 


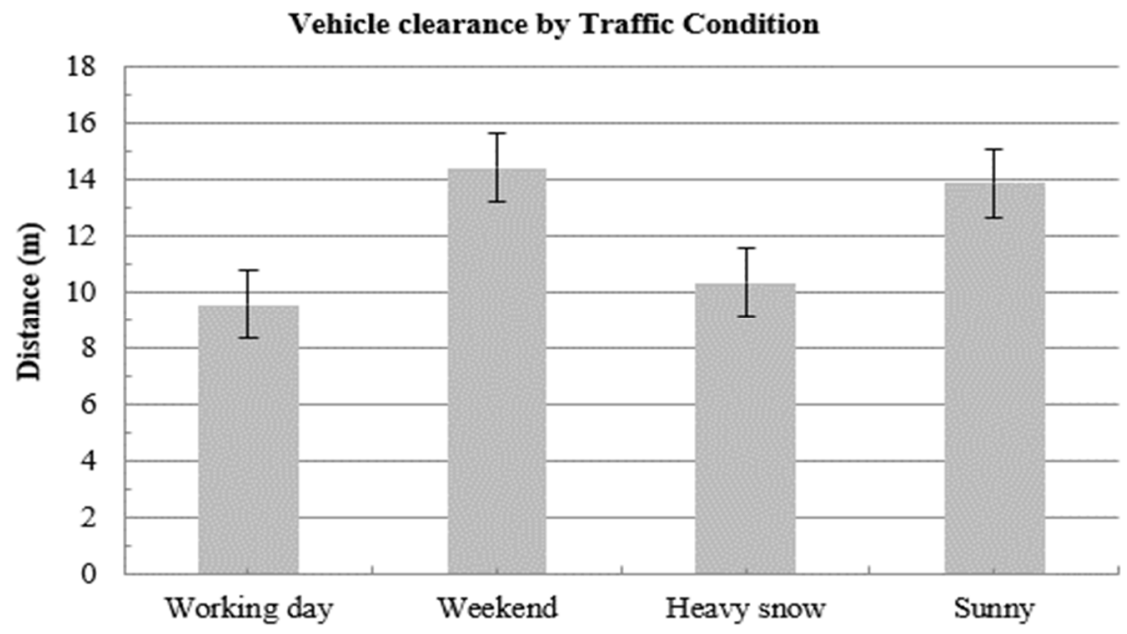

Figure 9. Vehicle clearance of naturalistic driving data.

\section{Discussion and Conclusions}

Commuter buses studies have rarely considered aspects other than the commuter line design and station setting. This study investigated the effects of two traffic scenarios and two weather conditions on speed and vehicle clearance. By using a Bonferroni correction for multiple comparisons, the results were adequate. Statistical tests were performed on speed and vehicle clearance data for four traffic statuses of urban roads when driving naturally.

\subsection{Speed}

In general, this study showed that the average speed of commuter buses would be lowest during both heavy snow $(10.34 \mathrm{~km} / \mathrm{h})$ or working days $(15.23 \mathrm{~km} / \mathrm{h})$, in the traffic environmental status Grade IV, and that the average speed on sunny days and the weekend was $16.93 \mathrm{~km} / \mathrm{h}$ and $14.14 \mathrm{~km} / \mathrm{h}$, respectively, in the traffic environmental status Grade IV. In particular, the average speed decreased from $43.31 \mathrm{~km} / \mathrm{h}$ (weekend) to $37.18 \mathrm{~km} / \mathrm{h}$ (working day) in Grade II, and from $28.71 \mathrm{~km} / \mathrm{h}$ (weekend) to $26.35 \mathrm{~km} / \mathrm{h}$ (working day) in Grade III. More specifically, the speed differences between working days and weekends varied by $8.96 \%$ (Grade III) and $16.49 \%$ (Grade II). Meanwhile, the average speed decreased from $21.12 \mathrm{~km} / \mathrm{h}$ (sunny) to $15.79 \mathrm{~km} / \mathrm{h}$ (snow) in Grade III, and from $44.62 \mathrm{~km} / \mathrm{h}$ (sunny) to $31.72 \mathrm{~km} / \mathrm{h}$ (snow) in Grade I. More specifically, the speed differences between sunny days and heavy snow days varied by $33.76 \%$ (Grade III) and 40.67\% (Grade I).

Working days in Grade IV and weekends in Grade IV resulted in the lowest and second-lowest average speeds, respectively. The speed differences between working days and weekends were not significant for Grades III and IV. In contrast, a difference between sunny and heavy snow days was present. Conversely, the speed differences between working days and weekends were significant in Grades I and II, particularly between sunny and heavy snow days. Furthermore, for these situations, the speed on weekends or sunny days was significantly higher than the scenarios where working days or heavy snow days were in Grade I.

For natural driving on urban roads (as in this study), heavy snow and working days can negatively affect speed. Therefore, policymakers and mobility experts should also consider the effect of the weather and traffic scenarios on speed behavior to decide which commuter schedule should be used under different traffic conditions. Furthermore, when a dynamic commuter schedule is used, it is advisable to use a delayed commuter schedule at each station, particularly when the weather is bad (heavy snow) or on working days.

A more accurate arrival time and shorter waiting time can improve the comfort of employees, reduce fatigue, and improve work efficiency [31]. When the speed of commuter buses on working days or heavy snow days is compared to that on weekends or sunny days, $12.69 \%$ and $37.80 \%$ of average delays, respectively, occur at the commuting station. The reason might be that the speed decreases and the saturated flow rate decreases by 
approximately $25 \%$ more in heavy snow than on sunny days [12]. Commuters may spend more than 5-10 min waiting for commuter buses, which usually makes them feel anxious on a working-day morning or very cold and uncomfortable on heavy snow days, or even catch a cold. Therefore, commuter vehicle managers should dynamically adjust the schedule of commuter buses according to the speed operation rules for commuter buses under different traffic conditions. This should be especially performed on weekends or in snowy weather to ultimately improve the comfort of passengers and improve the operational efficiency and service quality of commuter vehicles.

Moreover, speed also affects the development of commuter schedules. Speed is a crucial factor affecting commuter line design and station setting, which further determines the development of the commuter schedule. However, the scientific literature is inconclusive on the type of commuter schedule that should be preferred concerning speed situations from an accurate perspective. In general, the speed is lower during working or heavy snow days [32]. In contrast, some studies indicate an increase in travel time after heavy snowfall due to the counterbalancing factor the driving speed of urban roads after heavy snow tends to be lower. This result can be confirmed by those in this study. We found that commuter buses have the lowest speed on working and heavy snow days (natural driving on urban roads).

Thus, a fixed commuter schedule (where delays are unavoidable) does not necessarily improve the comfort and satisfaction of commuters. Furthermore, the speeding effect can also negatively affect other road users, such as buses and cars, or even cyclists and pedestrians (if no separate infrastructure exists). The results suggest that a dynamic commuter schedule based on speed can be used for commuter bus management purposes.

Because of all the differences between working days and weekends or snow and sunny days were significant, traffic scenarios and weather affect the average speed of commuter buses. During traffic scenarios for working days, the speed was generally lower than on weekends. In heavy snow weather, the speed was usually lower than that on sunny days. Late arriving at a commuter station is a basic reason leading to discontent; thus, we advise using a dynamic commuter schedule based on speed, especially when the weather is bad.

\subsection{Vehicle-to-VehicleDistance}

Commuter buses are expected to have a smaller vehicle clearance on working days or heavy snow days than on weekends and sunny days. In particular, the average vehicle clearance decreased from $3.25 \mathrm{~m}$ (weekend) to $2.66 \mathrm{~m}$ (working day) in Grade IV, and from $17.42 \mathrm{~m}$ (weekend) to $12.48 \mathrm{~m}$ (working day) in Grade I. Specifically, the vehicle clearance differences between working days and weekends varied by $22.18 \%$ (Grade IV) and 39.58\% (Grade I). Additionally, the average vehicle clearance decreased from $3.68 \mathrm{~m}$ (sunny) to $3.10 \mathrm{~m}$ (snow) in Grade IV, and from $14.89 \mathrm{~m}$ (sunny) to $10.35 \mathrm{~m}$ (snow) in Grade I, i.e., the vehicle clearance differences between sunny days and heavy snow days varied by $18.71 \%$ for Grade IV and $42.08 \%$ for Grade I.

Working days, but not heavy snow days in Grade IV, resulted in the lowest average vehicle clearance. This might be because drivers tend to anticipate leaving enough emergency braking space when driving on slippery roads due to heavy snow. Some scholars [33] reported having a larger vehicle clearance during bad weather. Here, the results indicate that drivers only maintain a large distance between cars if the weather is bad. Moreover, there is no difference between working days and weekends. In this way, the drivers can prevent a potential crash because they have more time to react (the time-to-collision is high). This can positively affect head-on collisions.

In contrast, working and heavy snow days resulted in the lowest and second-lowest average vehicle clearance, respectively; vehicle clearance can affect accident risk [34]. In general, the number of injury crashes will be higher when the vehicle clearance is small compared toa large distance. Some studies have indicated an increase in the number of crashes with a small vehicle clearance because vehicles with a small vehicle clearance always have insufficient safety distance to brake in case of an emergency. 


\section{Limitations and Further Research}

A different traffic flow will affect the average speed of commuter buses. Therefore, according to the division method adopted by most scholars, we divided the traffic environmental states into four groups (Grade I to Grade IV) according to traffic flow for research purposes; As for road geometry, since commuters mainly pick up employees to and from work on urban roads, our research is limited to urban roads, usually comprising two-way 4-lane, 6-lane, and 8-lane roads. This study focuses on the impact of heavy snow in northern China on the speed and spacing of commuter buses. Therefore, the primary focus is on comparisons between the two weather conditions of sunny days and heavy snow days. Follow-up research will also investigate the impacts of fog, rain, and other adverse weather conditions.

Currently, the research methods for driving behavior mainly include the natural driving behavior method, traffic accident data method, driving simulator test method, and field test method. Recently, the natural driving behavior method, which collects data on the natural driving state, has been increasingly applied. Natural driving behavior research is a method for collecting driving behavior in a natural driving state in a real traffic environment without external interference from driver behavior. This study considered the natural driving behavior method to collect data [35]; thus, the extracted data is real and accurate. Nevertheless, the data collection and experimental process were relatively complex [36]. In particular, it required substantial time to process and analyze the experimental data.

In this study, the speed and spacing of commuter buses were found to be different on working days and weekends under different traffic flow conditions, as well as being different on snowy and sunny days. These results can be used as a reference for adopting a dynamic commuter timetable. For example, we know that the commuter route and length are fixed, so we can calculate the time when the commuter arrives at each station later than usual, according to the decrease in the average running speed of vehicles in heavy snow, and dynamically adjust the commuter schedule when in heavy snow so that the commuter does not have to wait too long in the heavy snow to improve commuter comfort. Similarly, we can calculate a more accurate commuter schedule according to the commuter speed on sunny days and can improve commuter efficiency and save commuting costs for enterprises. However, since the driver is the operator of the commuter bus, the driver is crucial in determining parameters of interest (speed, safety distance, etc.). Therefore, we initially aimed to determine the speed and clearance rules of commuter buses under two different traffic scenarios (working days and weekends) and two weather conditions We will subsequently conduct an in-depth investigation into the reasons and influencing factors behind the law, in which drivers are the key research objects, such as driving habits and psychological factors. This will be carried out in the next research.

This paper found that the average speed of commuter buses would be lower on working days than on weekends in the same traffic environment status, helping optimize commuter schedules. However, we also find that the average speed of commuters is not the same on different weekdays (Monday to Friday). Therefore, the more detailed the average speed rule, the more accurate the commuter bus dynamic schedule can be obtained. Further research could focus on the differences in working days and their influence on the commuter schedule.

Conversely, bad weather conditions, such as heavy snow or little snow, affect the speed of traffic flow differently. Therefore, the commuter bus speed characteristics would also differ on different snow days, such as light snow or heavy snow. Moreover, considering this aspect could help to design accurate commuter bus dynamic schedules. To investigate this further, scholars should perform further observations and experiments.

Author Contributions: Conceptualization, Q.H. and S.F.; methodology, Q.H.; software, Q.H.; validation, Y.Z., Q.H. and Y.A.S.H.; formal analysis, Q.H.; investigation, Y.Z., Q.H. and G.Z.; resources, S.F.; data curation, S.F.; writing—original draft preparation, Q.H.; writing—review and editing, S.F.; 
visualization, G.Z. and Y.A.S.H.; supervision, Y.Z.; project administration, S.F.; funding acquisition, S.F. All authors have read and agreed to the published version of the manuscript.

Funding: This work was supported by the National Key Research and Development Program Project of China [grant number 2017YFC0803901].

Institutional Review Board Statement: The study was conducted in accordance with the Declaration of Helsinki, and the protocol was approved by the Ethics Committee of China Association for Ethical Studies (NO. 3965).

Informed Consent Statement: Informed consent was obtained from all subjects involved in the study.

Data Availability Statement: The data presented in this study are available on request from the corresponding author. The data are not publicly available due to privacy restrictions.

Conflicts of Interest: The authors declare no conflict of interest. The funders had no role in the design of the study; in the collection, analyses, or interpretation of data; in the writing of the manuscript, or in the decision to publish the results.

\section{References}

1. Mollu, K.; Biesbrouck, M.; Van Broeckhoven, L.; Daniëls, S.; Pirdavani, A.; Declercq, K.; Vanroelen, G.; Brijs, K.; Brijs, T. Priority rule signalization under two visibility conditions: Driving simulator study on speed and lateral position. Transp. Res. F 2018, 58, 156-166. [CrossRef]

2. Liu, C.; Qiao, J.Y.; Jin, X. Study on route optimization of commute buses based on ant colony algorithm. Logist. Technol. 2013, 32, 278-280.

3. Weng, C.W. One Company Work Commuter Car Path Problem Research Based on the Management Information System. Master's Thesis, Shanghai Jiao Tong University, Shanghai, China, 2017.

4. Gaodemap. Traffic Analysis Report of Q1 Major Cities in China in 2019; Institute of Sociology, Chinese Academy of Social Sciences, Intelligent Technology Laboratory of Urban Public Transport. 2019. Available online: https://www.takefoto.cn/viewnews-1762 233.html (accessed on 14 February 2022).

5. Li, J.; Lv, Y.B.; Ma, J.H.; Ren, Y. Factor analysis of customized bus attraction to commuters with different travel modes. Sustainability 2019, 11, 7065. [CrossRef]

6. Chaudhary, M.L. Commuters' perceptions on service quality of bus rapid transit systems: Evidence from the cities of Ahmedabad, Surat and Rajkot in India. Eur. Transp.-Trasp. Eur. 2020, 79. Available online: http://www.istiee.unict.it/sites/default/files/files/ Paper\%207\%20n\%2079.pdf (accessed on 14 February 2022).

7. Suman, H.K.; Bolia, N.B.; Tiwari, G. Analysis of the factors influencing the use of public buses in Delhi. J. Urban Plan. Dev. 2016, 142, 04016003. [CrossRef]

8. Yu, Q.; Zhang, H.; Li, W.; Song, X.; Yang, D.; Shibasaki, R. Mobile phone GPS data in urban customized bus: Dynamic line design and emission reduction potentials analysis. J. Clean. Prod. 2020, 272, 122471. [CrossRef]

9. Yin, Y.H.; Yu, H.Z.N.; Wang, J.G. Research on characteristics of Beijing road traffic flow based on GIS. Highw. Eng. 2020, 45, $102-108$.

10. Zhao, X.H.; Ren, G.C.; Chen, C.; Rong, J.; Chang, X. Comprehensive effects of adverse weather on driver on driving simulation technology. J. Chongqing Jiaotong Univ. (Nat. Sci.) 2019, 38, 90-95.

11. Maki, P.J. Adverse weather traffic signal timing. In Proceedings of the 69th Annual Meeting of the Institute of Transportation Engineers, Las Vegas, NV, USA, 1-4 August 1999.

12. Liu, L.L.; Weng, J.C.; Rong, J. Study on traffic flow characteristics of urban expressway under snowfall. Traffic Inf. Saf. 2012, 30, 10-14.

13. Wu, L.X.; Li, Y.X. Analysis on traffic flow characteristics of signalized intersections in Changchun under ice and snow conditions. Fujian Transp. Sci. Technol. 2019, 1, 116-118.

14. Yao, Y.J.; Han, N.C.; Ma, T.B.; Zhan, Z.H. Measurement method of vehicle speed based on single loop-coil. Instrum. Tech. Sens. 2016, 6, 104-107.

15. Liu, X.L.; Jiao, X.L.; Hu, Y.Z.; Hu, J.; Yu, T.T. Study on dynamic characteristics and coordinated control method of urban traffic flow. Traffic Enterpr. Manag. 2019, 34, 49-51.

16. Shin, E.J. Commuter benefits programs: Impacts on mode choice, VMT, and spillover effects. Transp. Policy 2020,94, 11-22. [CrossRef]

17. Wang, J.; Zhang, M. Identifying the service areas and travel demand of the commuter customized bus based on mobile phone signaling data. J. Adv. Transp. 2021, 2021, 6934998. [CrossRef]

18. Chen, L.; Ma, Z.; Li, Q.; Zhen, Q. Waiting decision behavior of commuters for bus transits based on prospect theory. J. Transp. Eng. A Syst. 2021, 147, 04021008. [CrossRef] 
19. Wang, Z.B.; Wang, S.C.; Lian, H.T. A route-planning method for long-distance commuter express bus service based on OD estimation from mobile phone location data: The case of the Changping Corridor in Beijing. Public Transp. 2021, 13, 101-125. [CrossRef]

20. Qiu, G.; Song, R.; He, S. Clustering passenger trip data for the potential passenger investigation and line design of customized commuter bus. IEEE Trans. Intell. Transp. Syst. 2019, 20, 3351-3360. [CrossRef]

21. Zhang, L.; Ma, J.; Liu, P.; Zhang, G. Study on the risk evaluation of commuter buses in coal enterprises based on GAHP. In Proceedings of the 19th COTA International Conference of Transportation Professionals (CICTP) - Transportation in China 2025, Nanjing, China, 6-8 July 2019; pp. 3500-3511.

22. Lyman, C.; Campbell, N.; Gonzales, E.J. Modeling the effect of new commuter bus service on demand and impact on greenhouse gas emissions: Application to Greater Boston. Transp. Res. Rec. 2019, 2673, 125-138. [CrossRef]

23. Antin, J.; Lee, S.; Hankey, J. Design of the in-Vehicle Driving Behavior and Crash Risk Study: In Support of the SHRP 2 Naturalistic Driving Study; Transportation Research Board of the National Academies: Washington, DC, USA, 2011.

24. Feng, S.M.; Huang, Q.J.; Zhang, Y.; Zhao, H. Driver's perception-decision-control model. J. Transp. Syst. Eng. Inf. Technol. 2021, 21, 41-47.

25. Shao, Y.M.; Xu, J.; Li, B.W.; Yang, K. Modeling the speed choice behaviors of drivers on mountainous roads with complicated shapes. Adv. Mech. Eng. 2015, 7, 862610. [CrossRef]

26. Jin, X.Q.; Wang, L.J.; Shao, Y. Headway spacing for different traffic flows. J. Dalian Jiaotong Univ. 2014, 35, 33-36.

27. Ma, Y.L.; Leng, X.; Hu, B.Y. Influence of in-vehicle information system operation on driver action distraction. J. Transp. Syst. Eng. Inf. Technol. 2015, 15, 204-209.

28. Cheng, G.Z.; Mo, X.Y.; Mao, C.Y. Urban road traffic safety evaluation method under the condition of ice and snowpavement. J. Transp. Syst. Eng. Inf. Technol. 2011, 11, 130-134.

29. Fisher, D.L.; Rizzo, M.; Caired, J.K.; Rizzo, M.; Lee, J.D. Handbook of Driving Simulation for Engineering, Medicine, and Psychology; CRC Press Taylor \& Francis Group: Boca Raton, FL, USA, 2011.

30. Available online: https://www.qcwxjs.com (accessed on 15 November 2021).

31. Ren, H.G.; Wang, Z.B.; Chen, Y.Y. Optimal express bus routes design with limited-stop services for long-distance commuters. Sustainability 2020, 12, 1669. [CrossRef]

32. Liu, C.X.; Zhang, Y.P.; Cheng, G.Z. Traffic flow characteristic analysis of signal intersection on the ice and snow condition. $J$. Wuhan Univ. Technol. 2014, 38, 806-815.

33. Montella, A. Identifying crash contributory factors at urban roundabouts and usingassociation rules to explore their relationships to different crash types. Accid. Anal. Prev. 2011, 43, 1451-1463. [CrossRef]

34. Xu, C.; Liu, P.; Wang, W.; Li, Z. Evaluation of the impacts of traffic states on crash risks on freeways. Accid. Anal. Prev. 2012, 47, 162-171. [CrossRef]

35. Liu, Z.Q.; Zhang, K.D.; Ni, J. Analysis and identification of drivers' difference in car-following condition based on naturalisticdrivingdata. J. Transp. Syst. Eng. Inf. Technol. 2021, 21, 48-55.

36. Fung, N.C.; Wallace, B.; Chan, A.D.C.; Goubran, R.; Porter, M.M.; Marshall, S.; Knoefel, F. Driver Identification Using Vehicle Acceleration and Deceleration Events from Naturalistic Driving of Older Drivers International Symposium on Medical Measurements and Applications (Memea); IEEE Publications: Rochester, MN, USA, 2017; pp. 33-38. [CrossRef] 